\title{
SISTEM INFORMASI PELAPORAN KERUSAKAN FASILITAS UMUM DI TERMINAL BERBASIS WEB
}

\author{
Diah Ayu Anjarwati ${ }^{1}$, Sri Dianing Asri ${ }^{2}$ \\ ${ }^{1,2}$ Universitas Mercu Buana
}

Gg. Asem, Pd. Ranggon, Kec. Cipayung, Kota Jakarta Timur, Daerah Khusus Ibukota Jakarta 13860

141815210018@student.mercubuana.ac.id, ${ }^{2}$ dianing.asri@mercubuana.ac.id

Abstrak-Unit Pengelola Terminal (UPT) Rawamangun yang berada di J1. Perserikatan, Rawamangun, Pulogadung, Jakarta Timur, merupakan pangkalan dari berbagai jenis kendaraan umum. Dari mulai angkutan kota hingga bus antarkota. Banyak fasilitas umum yang disediakan untuk pengunjung dan calon penumpang bus. Diantaranya seperti ruang tunggu, arena makan, serta ruang menyusui. Dengan demikan diperlukan perawatan-perawan terhadap fasilitas umum yang ada agar tetap memiliki nilai guna. Namun untuk memperhatikan semua fasilitas umum yang ada akan memakan waktu jika hanya suatu organisasi saja yang melakukannya. Maka dari itu diperlukan suatu sistem informasi dimana bisa menjadi tempat pelaporan dari kerusakan fasilitas umum yang ada di terminal. Sehingga laporan tersebut bisa sampai pada pihak yang berwenang untuk langsung diperbaiki. Website ini juga diharapkan lebih efisien karena bermanfaat untuk memudahkan masyarakat dalam berpartisipasi dengan melaporkan kerusakan yang ditemui, dengan adanya fitur-fitur serta konten yang membantu berbagi informasi antara masyarakat dengan pihak pengelola terminal.

Keywords - Terminal, pelaporan, fasilitas umum

Abstract-Rawamangun Terminal Management Unit (UPT) located at Jl. Perserikatan, Rawamangun, Pulogadung, East Jakarta, is a base for various types of public transportation. From starting city transportation to intercity buses. Many public facilities are provided for visitors and prospective bus passengers. Such as waiting rooms, dining areas, and nursing rooms. Thus, virgin care is needed for existing public facilities so that they still have use value. To pay attention to all public facilities that will take time if only the organization is done. Therefore we need an information system which can be a place of reporting of damage to public facilities in the terminal. Can report in the end approved for repair. This website is also expected to be more efficient because it is useful to facilitate the public in responding to the damage encountered, with features and content that helps share information between the community and the terminal manager.

Keywords - Terminals, reporting, public facilities

\section{PENDAHULUAN}

Salah satu terminal yang cukup sibuk akan kegiatan tersebut adalah Terminal Rawamangun. UPT (Unit Pengelola Terminal) Rawamangun berlokasikan di Jl. Perserikatan No. 1 RT 2/RW 8, Rawamangun, Pulogadung, Jakarta Timur. Dahulu terminal Rawamangun merupakan tempat penampungan terminal yang ada di sekitarnya. Karena bukan terminal utama, terminal Rawamangun tidak memiliki pul bus. Bus-bus yang masuk ke dalam terminal hanya singgah untuk "mengambil" penumpang.

Walau dengan kondisi seperti itu, terminal Rawamangun tetap memiliki banyak fasilitas umum yang disediakan untuk pengunjung dan calon penumpang bus. Diantaranya seperti ruang tunggu yang dilengkapi dengan arena makan, kipas angina, dan televisi. Terminal Rawamangun juga memiliki ruang tunggu khusus disabilitas, serta ruang menyusui yang dilengkapi AC dan toilet.
Fasilitas umum merupakan sarana bagi masyarakat dan juga dapat menentukan tingkat kenyamanan bagi para pengunjung dan calon penumpang. Jika fasilitas umum yang tersedia mengalami kerusakan atau bahkan sampai tidak bisa digunakan sebagaimana mestinya akan membuat pengunjung merasa tidak nyaman. Hal tersebut harus segera diselesaikan dengan melakukan perbaikan pada fasilitas yang mengalami penurunan nilai layak guna.

\section{METODE PENELITIAN}

\section{A. Teknik Pengumpulan Data}

Teknik pengumpulan data yang digunakan dalam penyusunan penelitian ini adalah :

1. Wawancara

Metode pengumpulan data dengan wawancara bertujuan untuk mengumpulkan informasi dengan melakukan tanya jawab secara langsung dengan DISHUB (Dinas Perhubungan) yang berada di UPT Rawamangun. 


\section{Studi Pustaka}

Metode ini di lakukan dengan cara memperoleh data dari buku-buku, jurnal tentang hal-hal pokok yang berhubungan dengan sistem informasi pelaporan fasilitas dan kendaraan umum yang akan dibuat atau permasalahan yang dihadapi dan nantinya dapat mendukung kelengkapan informasi yang dibutuhkan.

\section{B. Diagram Alir Penelitian}

Diagram alir di bawah ini merupakan langkahlangkah untuk mendukung proses penelitian, berikut tahapan penelitiannya:

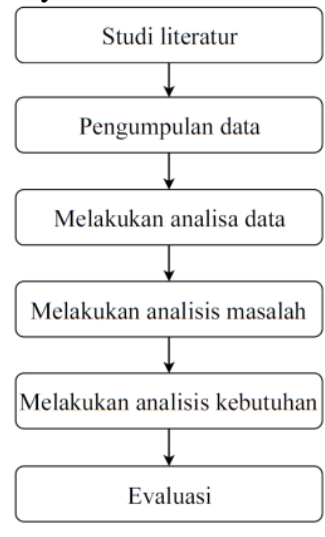

Gbr. 1 Tahapan Penelitian

1. Studi Literatur

Studi literatur digunakan sebagai landasan teori dalam penyelesaian masalah secara ilmiah. Studi literatur dilakukan untuk menambah wawasan dalam pengetahuan mengenai permasalahan yang akan dibahas dan menentukan metode yang cocok untuk memecahkan masalah yang sedang diteliti. Dalam tahap ini menggunakan berbagai jurnal dan sumber buku yang mendukung tentang penelitian ini yang menjadi referensi dan acuan dalam penelitian.

2. Pengumpulan Data

Tahapan selanjutnya adalah pengumpulan data yang nantinya digunakan untuk mendukung dan memecahkan permasalahan yang ada. Dalam pengumpulan data terlebih dahulu menetapkan sumber data, dalam penelitian ini menggunakan data primer sebagai pendukung sumber data, yaitu melalui wawancara kepada anggota DISHUB yang berada di UPT Rawamangun

3. Melakukan Analisa Data

Melakukan analisa data bertujuan untuk menganalisis data apa saja yang didapatkan dari hasi pengumpulan data di UPT Rawamangun. Analisis ini bertujuan untuk menemukan informasi yang bermanfaat untuk penelitian, kemudian data tersebut diurutkan dari masalah yang didapatkan hingga melakukan analisis kebutuhan yang merupakan solusi dari masalah yang ada.

4. Melakukan Analisis Masalah

Analisis ini bertujuan untuk menemukan masalah yang ada di UPT Rawamangun dan berhubungan dengan fasilitas umum yang terdapat di sana. Data masalah yang didapatkan juga berdasarkan keterangan dari para pengunjung.

5. Melakukan Analisis Kebutuhan

Analisis kebutuhan atas masalah yang sudah dianalisis, sehingga menghasilkan sebuah rancangan sistem yang akan dibuat untuk menyelesaikan masalah tersebut.

6. Evaluasi

Dari hasil analisi kebutuhan didapatkan sebuah rancangan sistem yang memenuhi kebutuhan. Selanjutnya dilakukan sebuah evaluasi, apakah sistem yang dirancang sudah dapat memenuhi kebutuhan pengunjung terminal Rawamangun.

\section{HASIL DAN PEMBAHASAN}

\section{A. Analisa Kebutuhan}

Tahap analisis sistem merupakan salah satu usaha mengidentifikasi kebutuhan dan spesifikasi sistem yang akan diciptakan. Di dalamnya akan dijabarkan apa saja entitas yang dilibatkan, proses yang dijalankan, serta keluaran yang akan dihasilkan.

Berdasarkan analisis masalah yang dijabarkan di atas, maka sistem yang dibuat adalah sistem informasi pelaporan kerusakan pada fasilitas umum dengan spesifikasi sistem sebagai berikut:

1. Sistem yang akan dibangun yaitu berbasis web sehingga mudah diakses dimana-mana.

2. Sistem menyediakan layanan untuk pengguna dapat mengetahui status dari laporan yang di ajukan.Sistem menyediakan fitur dimana laporan yang ternyata tidak benar adanya akan langsung didrop oleh petugas.

3. Sistem memberikan informasi mengenai laporan yang sudah diselesaikan di setiap terminal yang terdaftar.

\section{B. Perancangan Sistem}

Perancangan sistem yang merupakan analisis kebutuhan fungsional ini akan mencakup Diagram UML:

\section{Use Case Diagram}

"Diagram use-case adalah diagram yang menampilkan actor, use case dan relasi diantara keduanyadalam sebuah sistem. Use case diagram menggambarkan ruang lingkup dari sistem yang akan dibangun dan merupakan sarana komunikasi dengan pengguna akhir untuk mendapatkan pemahaman yang lebih baik tentang sistem yang akan dibuat." [10] 


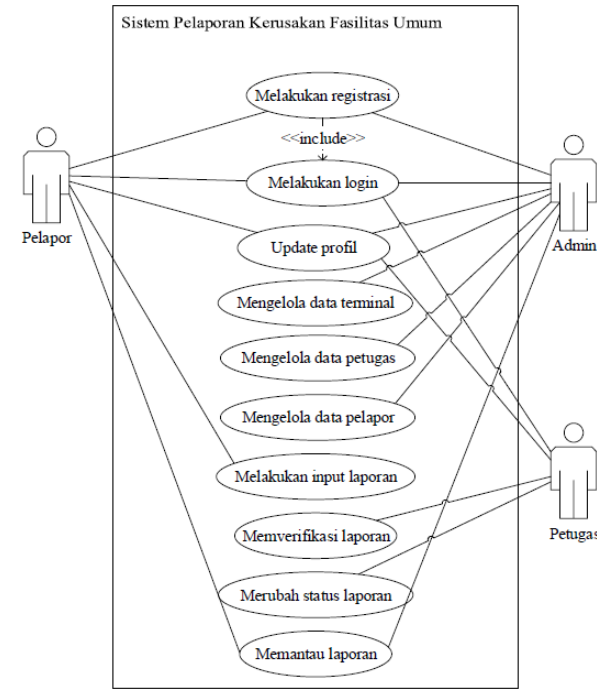

Gbr. 2 Use Case Diagram

2. Activity Diagram

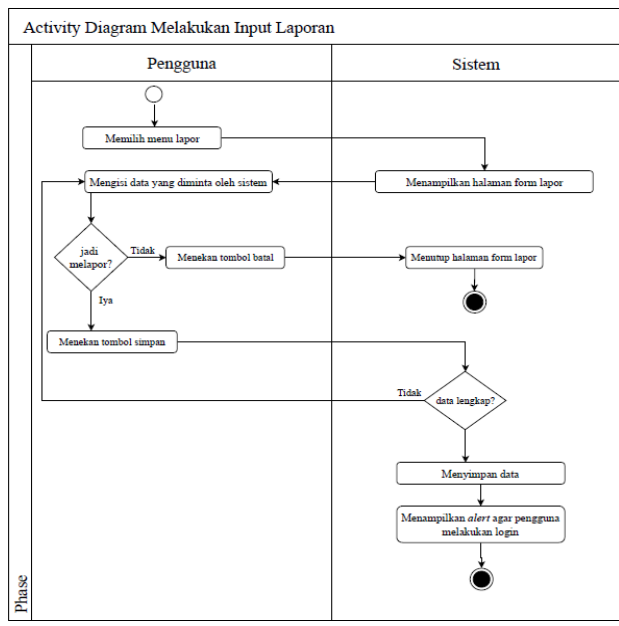

Gbr. 3 Activity Diagram Melakukan Input Laporan

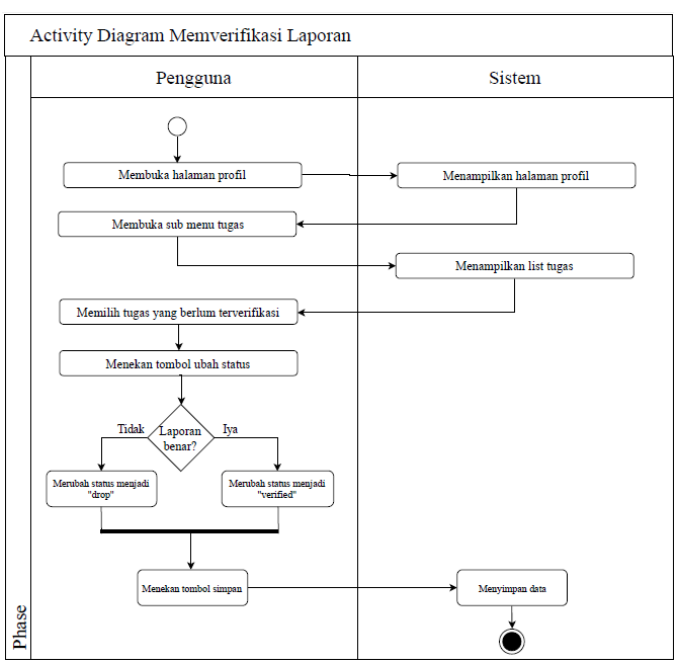

Gbr. 4 Activity Diagram Memverifikasi Laporan

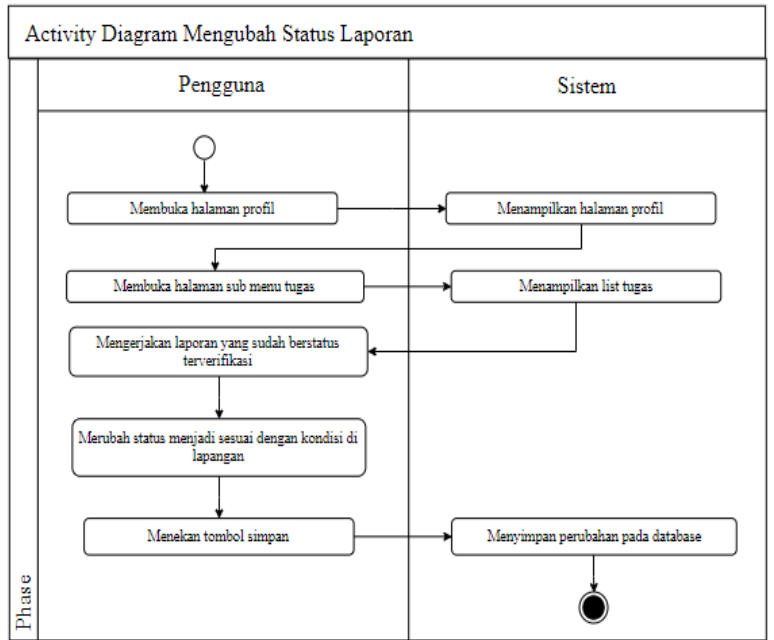

Gbr. 5 Activity Diagram Mengubah Status Laporan

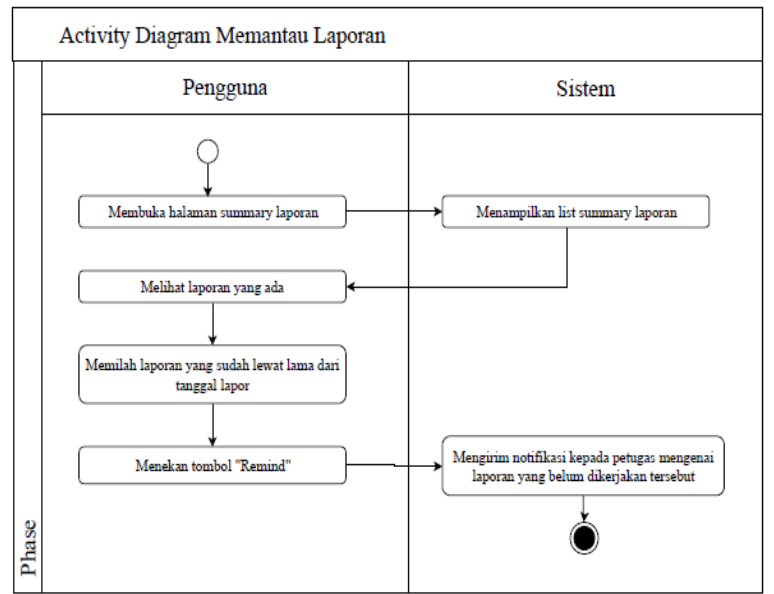

Gbr. 6 Activity Diagram Memantau Laporan

3. Class Diagram

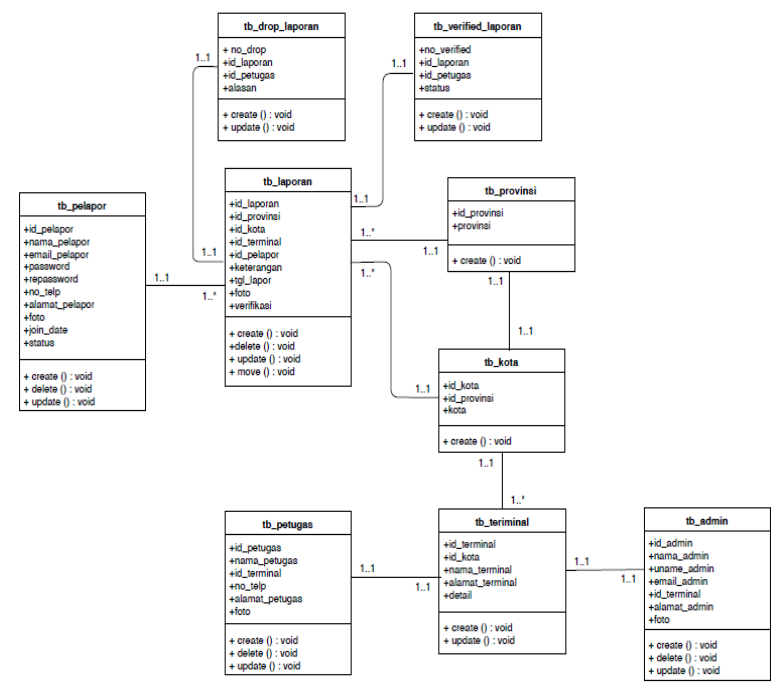

Gbr. 7 Class Diagram 
4. Perancangan Antar Muka

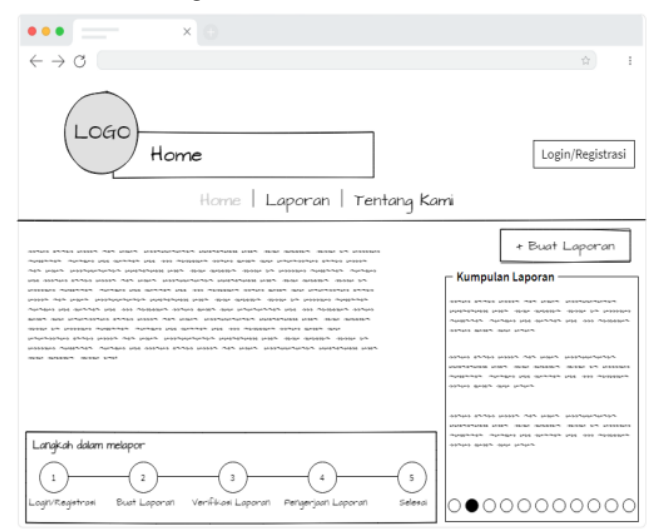

Gbr. 8 Tampilan Halaman Utama (Home)

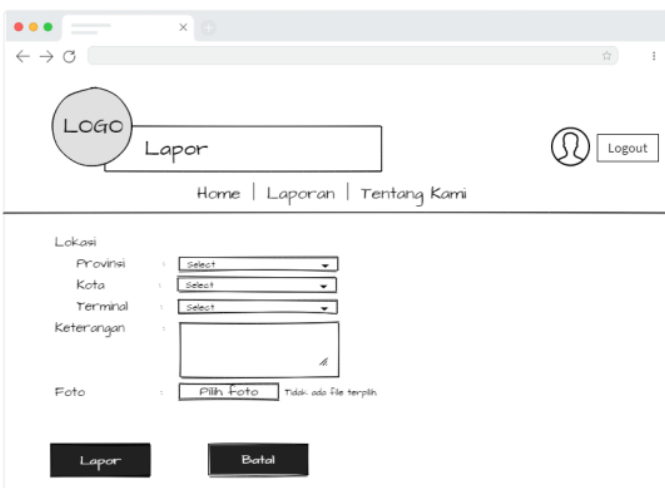

Gbr. 9 Tampilan Halaman Lapor

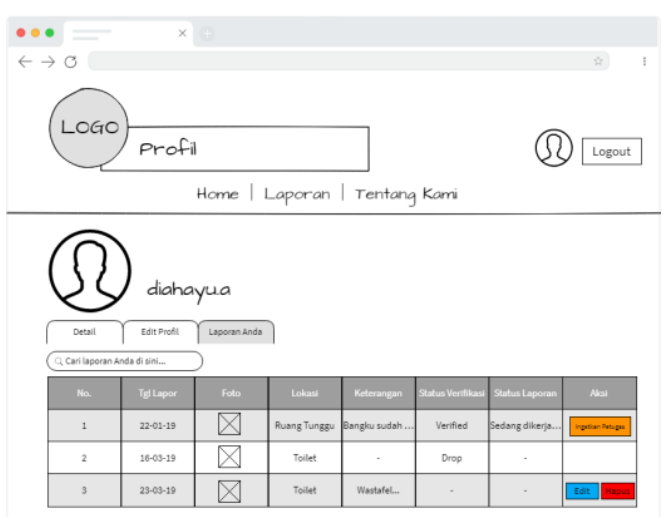

Gbr. 10 Tampilan Halaman Laporan Pada User

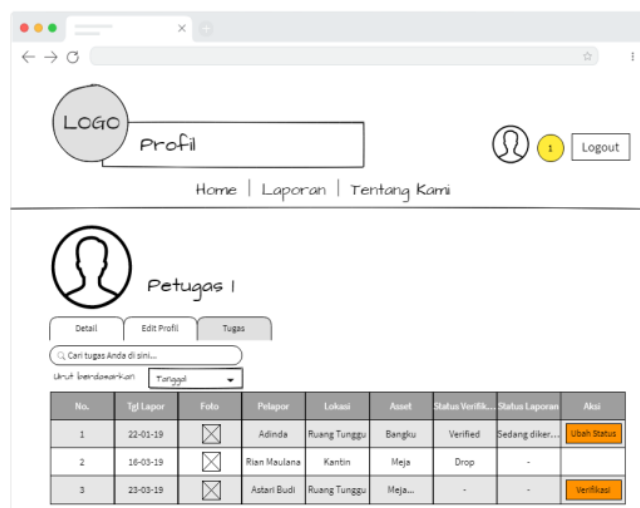

Gbr. 11 Tampilan Halaman Laporan Pada Petugas

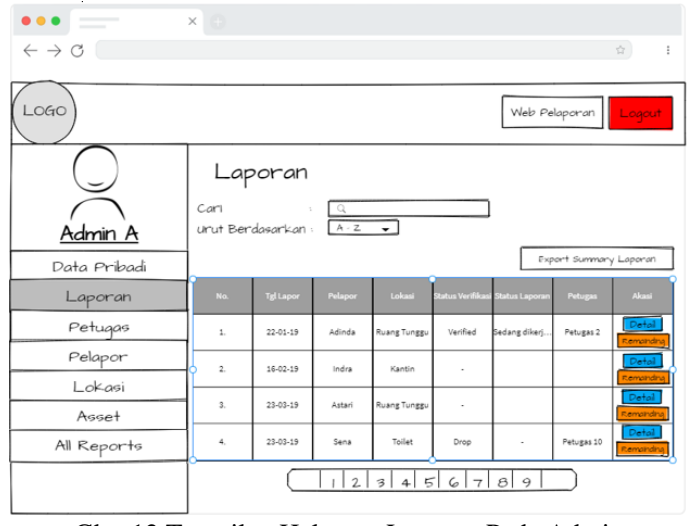

Gbr. 12 Tampilan Halaman Laporan Pada Admin

5. Perancangan Keluaran (Output)

TABEL 1

TABEL PERANCANGAN KELUARAN (OUTPUT)

\begin{tabular}{|c|c|c|}
\hline No. & Kasus & Tabel \\
\hline 1 & Daftar seluruh petugas & tb_petugas \\
\hline 2 & Daftar seluruh pelapor & tb_pelapor \\
\hline 3 & Summary laporan & $\begin{array}{l}\text { tb_laporan, } \\
\text { tb_drop_laporan, } \\
\text { tb_verrified_lapora } \\
\text { n,tb_petugas }\end{array}$ \\
\hline 4 & $\begin{array}{l}\text { Daftar laporan yang sudah } \\
\text { diselesaikan oleh petugas }\end{array}$ & $\begin{array}{l}\text { tb_petugas, } \\
\text { tb_verified_laporan, } \\
\text { tb_laporan }\end{array}$ \\
\hline 5 & $\begin{array}{l}\text { Daftar laporan yang didrop } \\
\text { oleh petugas }\end{array}$ & $\begin{array}{l}\text { tb_laporan, } \\
\text { tb_petugas, } \\
\text { tb_drop_laporan }\end{array}$ \\
\hline 6 & $\begin{array}{l}\text { Daftar lokasi dengan asset } \\
\text { yang ada di dalamnya }\end{array}$ & tb_lokasi, tb_asset \\
\hline 7 & $\begin{array}{l}\text { Daftar pelapor beserta } \\
\text { laporannya }\end{array}$ & $\begin{array}{l}\text { tb_laporan, } \\
\text { tb_pelapor }\end{array}$ \\
\hline 8 & Daftar seluruh petugas & tb_petugas \\
\hline 9 & Daftar seluruh pelapor & tb_pelapor \\
\hline 10 & Summary laporan & $\begin{array}{l}\text { tb_laporan, } \\
\text { tb_drop_laporan, } \\
\text { tb_verrified_lapora } \\
\text { n, tb_petugas }\end{array}$ \\
\hline
\end{tabular}

\section{IV.PENUTUP}

Terminal merupakan sarana yang disediakan pemerintah demi mengurangi kemacetan yang ada dengan menaiki kendaraan umum. Website ini pun membantu masyarakat agar lebih nyaman jika berada di terminal dengan fasilitas umum yang baik dan memadai. Website ini tentu masih banyak kekurangan, semoga di penelitian yang akan datang dapat dibentuk sebuah aplikasi dimana pengguna bisa merasa lebih mudah lagi dalam menyampaikan pelaporan nya kepada pihak pengurus terminal.

\section{UCAPAN TERIMA KASIH}

Ucapan termia kasih ditujukan kepada seluruh pihak terkait yang turut membantu dengan dukungan baik itu moril maupun materil. 


\section{REFERENSI}

[1] Rinaldy Maulidiansyah, Deny Fauzy Rakhman, Muhammad Ali Ramdhani, "Aplikasi Pelaporan Kerusakan Jalan Tol Menggunakan Layanan Web Service Berbasis Android," vol. X, no. 1, 2017.

Page | 156 [2] Agus Kurniawan. 2014. "Pemrograman Java Tingkat Lanjut". Yogyakarta. Penerbit ANDI Yogyakarta.

[3] Firman Ardiansyah, Asep Mulyana, Faqih Zulfikar, 2013 , "Perancangan dan Implementasi Sistem Pengaduan Masyarakat Berbasis Web Menggunakan Google Maps API".

[4] Yohanes Erwin Dari, 2017, "Sistem Pelaporan Kondisi Fasilitas Kampus dengan Menggunakan Wireless Positioning".

[5] Muhammad Fathul Mubarak, 2017, "Aplikasi Pelaporan Pelayanan Publik Berbasis Android (Studi Kasus: Ombudsman Makassar)".

[6] Setiawan Prakoso, 2016, "Peracangan Aplikasi Pelaporan Kerusakan Prasarana Berbasis Android Menggunakan GCM (Google Cloud Messaging) (Studi Kasus: Dinas Kependudukan dan Catatan Sipil Kota Salatiga).

[7] Andi Jumardi, Achmad Solichin, "Prototipe Palikasi Layanan Pengaduan Masyarakat Berbasis Android dan Web Service," Jurnal Telematika Mkom, vol. 8, No.1, Maret 2016.

[8] Elisa Usada, Yana Yuniarsyah, Noor Rifani, "Rancang Bangun Sistem Informasi Jadwal Perkuliahan Berbasis JQuery Mobile dengan Menggunakan PHP dan MySQL," Jurnal Infotel, vol. 4, No. 2, 2012.

[9] Muzi Burrakhman, Indah Fitri Astuti, Dyna Marisa Khairina. 2016. "Rancang Bangun Sistem Informasi Donor Darah Berbasis Web (Studi Kasus: Unit Kegiatan Mahasiswa Korps Sukarela Universitas Mulawarman. Jurnal Informatika Mulawarman)." 11 (1)

[10] Handrie Noprisson, "Analisis Sistem Dengan 4 Diagram UML (Studi Kasus: Sistem Informasi Akademik Laboratorium Praktikum Komputer)," 